Article

\title{
ent-Pimarane and ent-Kaurane Diterpenes from Aldama discolor (Asteraceae) and Their Antiprotozoal Activity
}

\author{
Mauro S. Nogueira ${ }^{1,+}$, Fernando B. Da Costa ${ }^{2}$, Reto Brun ${ }^{3,4}$, Marcel Kaiser ${ }^{3,4}$ \\ and Thomas J. Schmidt ${ }^{1, *}$ \\ 1 Institute of Pharmaceutical Biology and Phytochemistry (IPBP), University of Münster, \\ PharmaCampus Corrensstraße 48, Münster D-48149, Germany; nogueira@uni-muenster.de \\ 2 AsterBioChem Research Team, Laboratory of Pharmacognosy, School of Pharmaceutical Sciences of \\ Ribeirão Preto, USP, Av. do Café s/n, Ribeirão Preto-SP 14040-903, Brazil; febcosta@fcfrp.usp.br \\ 3 Swiss Tropical and Public Health Institute (Swiss TPH), Socinstr. 57, Basel CH-4051, Switzerland; \\ reto.brun@unibas.ch (R.B.); marcel.kaiser@unibas.ch (M.K.) \\ 4 University of Basel, Petersplatz 1, Basel CH-4003, Switzerland \\ * Correspondence: thomschm@uni-muenster.de; Tel.: +49-251-83-33378 \\ $+\quad$ This work is part of the doctoral thesis (Mauro Nogueira da Silva, University of Münster, 2016). \\ Academic Editor: Derek J. McPhee \\ Received: 30 August 2016; Accepted: 13 September 2016; Published: 15 September 2016
}

\begin{abstract}
Aldama discolor (syn.Viguiera discolor) is an endemic Asteraceae from the Brazilian "Cerrado", which has not previously been investigated for its chemical constituents and biological activity. Diterpenes are common secondary metabolites found in Aldama species, some of which have been reported to present potential antiprotozoal and antimicrobial activities. In this study, the known ent-3- $\alpha$-hydroxy-kaur-16-en-18-ol (1), as well as three new diterpenes, namely, ent-7-oxo-pimara-8,15-diene-18-ol (2), ent-2S,4S-2-19-epoxy-pimara-8(3),15-diene-7 $\beta$-ol (3) and ent-7-oxo-pimara-8,15-diene-3 $\beta$-ol (4), were isolated from the dichloromethane extract of A. discolor leaves and identified by means of MS and NMR. The compounds were assayed in vitro against Trypanosoma brucei rhodesiense, T. cruzi and Leishmania donovani, Plasmodium falciparum and also tested for cytotoxicity against mammalian cells (L6 cell line). The ent-kaurane 1 showed significant in vitro activity against both $P$. falciparum $\left(\mathrm{IC}_{50}=3.5 \mu \mathrm{M}\right)$ and L. donovani $\left(\mathrm{IC}_{50}=2.5 \mu \mathrm{M}\right)$ and ent-pimarane 2 against $P$. falciparum $\left(\mathrm{IC}_{50}=3.8 \mu \mathrm{M}\right)$. Both compounds returned high selectivity indices (SI >10) in comparison with L6 cells, which makes them interesting candidates for in vivo tests. In addition to the diterpenes, the sesquiterpene lactone budlein A (5), which has been reported to possess a strong anti-T. b. rhodesiense activity, was identified as major compound in the A. discolor extract and explains its high activity against this parasite (100\% growth inhibition at $2 \mu \mathrm{g} / \mathrm{mL})$.
\end{abstract}

Keywords: Aldama discolor; Viguiera discolor; Asteraceae; ent-pimarane; ent-kaurane; antiprotozoal activity; Trypanosoma brucei rhodesiense; Trypanosoma cruzi; Leishmania donovani; Plasmodium falciparum

\section{Introduction}

Aldama La Llave [1], Syn.Viguiera Kunth, is a large American genus with about 180 species, which are widespread from North America until Argentina, but mostly concentrated in Mexico, the Andes and upland areas of Brazil [2]. It must be noted that most of this work refers to Aldama as Viguiera, which has been re-classified in 2011 in the course of a taxonomic reinvestigation of the genus [1]. In the last two decades, several species of Aldama have been chemically investigated with numerous articles focusing on Central and South American species, but not many have been published on the Brazilian species. For $A$. discolor (previously referred to as $V$. discolor), a species occurring in 
the Brazilian "Cerrado" habitats, neither the chemical investigation of its secondary metabolites nor investigations on its biological activity have been described before.

The main classes of secondary metabolites known from the genus so far are terpenoids, i.e., sesquiterpene lactones (STLs), represented mainly by germacranolides, heliangolides and furanoheliangolides [3-7], as well as diterpenes, whose presence has been largely described in the genus. Among the diterpenes, ent-kauranes are the most common types [3,6,8-11], although ent-beyerane, ent-atisane [12,13] and trachylobane [14] have also been described. Pimarane diterpenes have been found only in A. pinnatilobata [15] and A. arenaria [16,17].

Several biologically-active secondary metabolites have been described as constituents of different species of Aldama. Although only a few Aldama species have been investigated, the bioactivities found are diverse, such as trypanocidal [10,17], cytotoxic [18], antimicrobial [19,20], anti-inflammatory [21], insecticide [22,23] and inhibition of vascular smooth muscle contractility [24].

Eukaryotic unicellular ("protozoan") parasites are known to cause infectious diseases, such as Human African trypanosomiasis (HAT), Chagas disease, leishmaniasis and malaria. These infections are responsible for a large number of deaths and a considerable contribution to the world-wide burden of disease, especially in impoverished regions of tropical countries. The treatment of these diseases is hampered, in many cases, by the use of old drugs, with low safety, by insufficient availability of drugs or complicated treatment regimens, or by the emergence of parasite resistance against the few existing therapeutics. Hence, there is an urgent need to find new drug candidates to be developed into new safe, efficient and available therapies. Natural products (NP) from plants of the Asteraceae family, especially sesquiterpene lactones (STLs) and diterpenes, have frequently been reported to present antiparasitic properties [25].

Previous reports on the antiprotozoal activities of some Aldama species highlighted active NP, such as ent-kaur-16-en-19-oic acid [10] against Trypanosoma cruzi in vitro, ent-15-pimarene-8 $\beta$, 19-diol [17] against Trypanosoma cruzi in vivo and budlein A against T. brucei rhodesiense in vitro [26]. On the basis of this reported biological potential, the present work, which is part of a larger study of in vitro screening of various Asteraceae from Brazilian "Cerrado" for antiprotozoal activity [27,28], reports on terpenoid constituents isolated from the dichloromethane extract of Aldama discolor and their antiprotozoal activity.

\section{Results}

\subsection{Antiprotozoal Activity of A. discolor Crude Extracts}

As part of an extensive screening of Asteraceae from the Brazilian "Cerrado", extracts obtained from the leaves of Aldama discolor with solvents of different polarity (n-hexane (Hex), dichloromethane (DCM), ethyl acetate (EtOAc) and methanol $(\mathrm{MeOH})$ ) were tested for in vitro activity against Trypanosoma brucei rhodesiense (bloodstream trypomastigotes), T. cruzi (intracellular amastigotes), Leishmania donovani (axenic amastigotes) and Plasmodium falciparum (intraerythrocytic forms). Each extract was tested at two concentrations, 2 and $10 \mu \mathrm{g} / \mathrm{mL}$, for growth inhibitory activity (\% GI) against the various parasites. The results are presented in Table 1. It becomes obvious that all extracts presented a considerable activity against $T$. $b$. rhodesiense, which showed $100 \%$ growth inhibition already at $2 \mu \mathrm{g} / \mathrm{mL}$ of the DCM, the EtOAc, as well as the $\mathrm{MeOH}$ extract. L. donovani and P. falciparum were less strongly affected by the low concentration, but also quite susceptible to $10 \mu \mathrm{g} / \mathrm{mL}$ of all extracts, while T. cruzi was not affected by any of the extracts. For isolation and characterization of the potentially active chemical constituents, the DCM extract was chosen. 
Table 1. In vitro growth inhibition (\%) of Aldama discolor crude extracts against T. b. rhodesiense, T. cruzi, L. donovani and P. falciparum. DCM, dichloromethane.

\begin{tabular}{|c|c|c|c|c|c|c|c|c|c|}
\hline \multirow{2}{*}{ Extract } & \multicolumn{2}{|c|}{ T.b. rhodesiense } & \multicolumn{2}{|c|}{ T. cruzi } & \multicolumn{2}{|c|}{ L. donovani } & \multicolumn{2}{|c|}{ P. falciparum } & \multirow{2}{*}{ Yield (\%) ${ }^{a}$} \\
\hline & $2 \mu \mathrm{g} / \mathrm{mL}$ & $10 \mu \mathrm{g} / \mathrm{mL}$ & $2 \mu \mathrm{g} / \mathrm{mL}$ & $10 \mu \mathrm{g} / \mathrm{mL}$ & $2 \mu \mathrm{g} / \mathrm{mL}$ & $10 \mu \mathrm{g} / \mathrm{mL}$ & $2 \mu \mathrm{g} / \mathrm{mL}$ & $10 \mu \mathrm{g} / \mathrm{mL}$ & \\
\hline Hex & 31.2 & 100.0 & 0.0 & 6.8 & 25.0 & 86.9 & - & 99.8 & 3.0 \\
\hline DCM & 100.0 & 100.0 & 0.0 & 0.0 & 21.1 & 86.4 & 5.7 & 99.7 & 28.0 \\
\hline EtOAc & 100.0 & 99.8 & 6.9 & 14.8 & 14.2 & 87.8 & 17.8 & 100.0 & 25.2 \\
\hline $\mathrm{MeOH}$ & 100.0 & 100.0 & 0.0 & 5.4 & 34.1 & 69.0 & 45.2 & 87.4 & 9.4 \\
\hline
\end{tabular}

${ }^{a}$ Percentage of dried crude extract in relation to the pulverized dried plant material. All extracts were prepared with $500 \mathrm{mg}$ of the plant material.

\subsection{Isolation and Characterization of the Compounds}

Separation of the DCM extract of Aldama discolor leaves afforded the known ent-3- $\alpha$-hydroxy-kaur16-en-18-ol (1) [29] and three diterpenes of the ent-pimarane type (2 4 (Figure 1)), which have not previously been described. Besides the diterpenes, a fraction consisting of almost pure budlein A (5) was obtained, which was identified by its HRESI mass spectrum obtained in direct comparison with an authentic reference sample by UHPLC/+ESI-QqTOF/MS (Figure S1, Supplementary Materials).
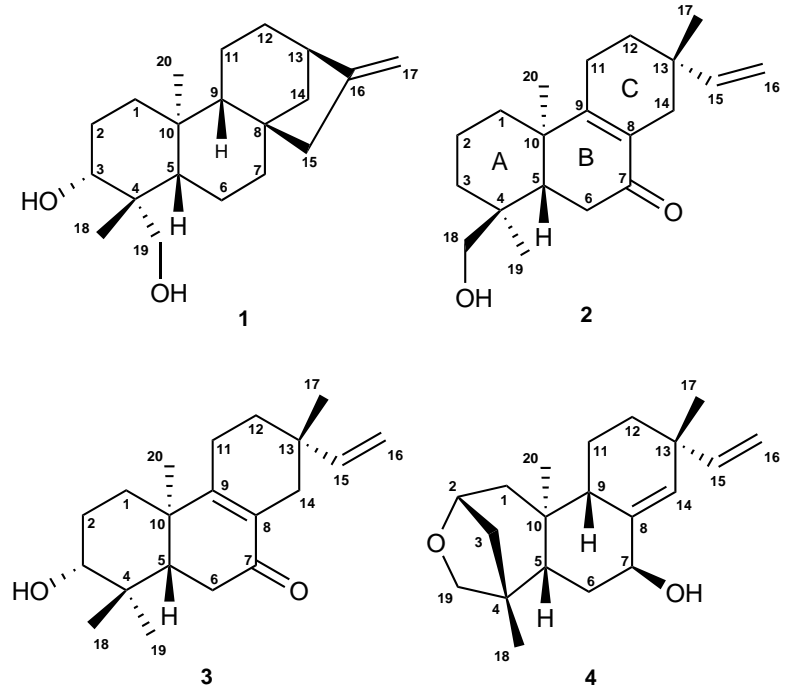

Figure 1. Chemical structures of diterpenes 1-4.

Diterpene 1 (ent-3- $\alpha$-hydroxy-kaur-16-en-18-ol) was unambiguously identified by its NMR spectra (for ${ }^{1} \mathrm{H}$ and ${ }^{13} \mathrm{C}-\mathrm{NMR}$ data, see Table 2 ) and exact mass data $\left([\mathrm{M}+\mathrm{H}]^{+}\right.$at $\mathrm{m} / z$ 305.2494; calculated for $\mathrm{C}_{20} \mathrm{H}_{31} \mathrm{O}_{2}: \mathrm{m} / z$ 305.2481; Figure S2, Supplementary Materials) in comparison with published data [29]. The relative configuration of $\mathbf{1}$ was furthermore confirmed by a 2D 1H/1H NOESY spectrum (Figure S8, Supplementary Materials), and the assignment of its absolute configuration was confirmed by its negative optical rotation $\left([\alpha]_{D}^{24}=-20.6\right)$, which was in agreement with the literature $[29,30]$.

In case of Compounds 2, 3 and 4, the presence of further diterpenes was clear from the exact mass data, as well as the ${ }^{13}$ C-NMR and HSQC spectra (Figures S11, S12, S18, S19, S26 and S27, Supplementary Materials) from which the number of rings and double bonds could be deduced by means of the hydrogen deficiency index, which pointed towards the presence of a pimarane-type carbon skeleton. Their affiliation to the pimar-15-ene type became clear in all three cases by the presence of an ABXspin system in their ${ }^{1} \mathrm{H}-\mathrm{NMR}$ spectra (Figures S10, S17 and S25, Supplementary Materials) and the carbon resonances of C-15 and C-16 in the ${ }^{13} \mathrm{C}-\mathrm{NMR}$ spectral data due to a terminal vinyl group (Table 2). 
Table 2. ${ }^{13} \mathrm{C}-\mathrm{NMR}$ and ${ }^{1} \mathrm{H}-\mathrm{NMR}$ spectroscopic data for 1-4 (150 and $\left.600 \mathrm{MHz}, \mathrm{CDCl}_{3}\right)$.

\begin{tabular}{|c|c|c|c|c|c|c|c|c|c|c|c|c|}
\hline & \multicolumn{3}{|c|}{$1^{a}$} & \multicolumn{3}{|c|}{2} & \multicolumn{3}{|c|}{3} & \multicolumn{3}{|c|}{4} \\
\hline & $\delta^{13} \mathrm{C}$ & $\delta^{1} \mathbf{H}$ & $J(\mathrm{~Hz})$ & $\delta^{13} \mathrm{C}$ & $\delta^{1} \mathbf{H}$ & $J(\mathrm{~Hz})$ & $\delta^{13} \mathrm{C}$ & $\delta^{1} \mathbf{H}$ & $J(\mathrm{~Hz})$ & $\delta^{13} \mathrm{C}$ & $\delta^{1} \mathbf{H}$ & $J(\mathrm{~Hz})$ \\
\hline \multirow[t]{2}{*}{1} & 38.6 & $\beta 0.89$ ddd & & 35.5 & a $1.84 \mathrm{ddd}$ & $16.6,12.8,3.8$ & 34.3 & $\alpha 1.88 \mathrm{dt}$ & $13,3.5$ & 36.8 & $\alpha 1.79 \mathrm{~m}$ & $13,11,3.6$ \\
\hline & & $\alpha 1.87 \mathrm{ddd}$ & & & b $1.28 \mathrm{ddd}$ & $16.6,12.8,4.1$ & & $\beta 1.42$ ddd & $13,4.2,3.5$ & & $\beta 1.21 \mathrm{~m}$ & $13,6,2.7$ \\
\hline \multirow[t]{2}{*}{2} & 27.9 & $\beta 1.84$ ddd & $13.4,11.8,3.6$ & 18.3 & a $1.65 \mathrm{dt}$ & $13.8,3.8$ & 27.4 & $\alpha 1.69$ ddd & $13.3,11.7,3.5$ & 81 & $\alpha 3.53 \mathrm{ddd}$ & $11.5,4.6,1.3$ \\
\hline & & $\alpha 1.71 \mathrm{ddd}$ & $13.4,8,4.4$ & & $\mathrm{~b} 1.71 \mathrm{dt}$ & $13.8,3.5$ & & $\beta 1.77 \mathrm{dq}$ & $13.3,3.9$ & & & \\
\hline \multirow[t]{2}{*}{3} & 81.1 & 3.42 ddd & $11.8,4.4,1.3$ & 34.6 & a $1.33 \mathrm{ddt}$ & $12.8,3.8,1.3$ & 78.1 & $3.29 \mathrm{dd}$ & $11.7,4.4$ & 28.1 & a $1.74 \mathrm{~m}$ & \\
\hline & & & & & b 1.52 ddd & $13.8,12.8,4.2$ & & & & & b 1.78 ddd & $13.2,3.6,1.8$ \\
\hline 4 & 43.1 & & & 37.7 & & & 38.9 & & & 42.4 & & \\
\hline 5 & 55.9 & $0.87 \mathrm{ddd}$ & $11.8,6,1.7$ & 43.2 & $2.08 \mathrm{dd}$ & $13.4,4.5$ & 49.1 & $1.69 \mathrm{dd}$ & $11.7,3.9$ & 47.5 & $1.71 \mathrm{~m}$ & \\
\hline \multirow{2}{*}{6} & 20.2 & $\beta 1.30 \mathrm{ddd}$ & $16,11.8,3.8$ & 35.3 & $\alpha 2.37 \mathrm{~m}$ & & 35.1 & $\alpha 2.42 \mathrm{dd}$ & $17.7,11.7$ & 28.9 & $\alpha 1.55 \mathrm{~m}$ & \\
\hline & & $\alpha 1.64 \mathrm{~m}$ & & & $\beta 2.42 \mathrm{~m}$ & & & $\beta 2.51 \mathrm{dd}$ & $17.7,3.9$ & & $\beta 1.88 \mathrm{dt}$ & $13.9,3.8$ \\
\hline \multirow[t]{2}{*}{7} & 41.5 & $\beta 1.47 \mathrm{~m}$ & & 199.8 & & & 199.8 & & & 72.8 & $\alpha 4.25 \mathrm{dd}$ & $6.8,3.8$ \\
\hline & & & $\alpha 1.51 \mathrm{~m}$ & & & & 175.2 & & & 176.2 & & \\
\hline 8 & 44.1 & & & 129.1 & & & 129.5 & & & 140.1 & & \\
\hline 9 & 56 & $1.03 \mathrm{~d}$ & 6.9 & 165.8 & & & 164.7 & & & 46.7 & $2.05 \mathrm{ddd}$ & $10.2,6.4,2.1$ \\
\hline 10 & 38.9 & & & 39.5 & & & 39.5 & & & 38.1 & & \\
\hline \multirow[t]{2}{*}{11} & 18.5 & $\beta 1.62 \mathrm{~m}$ & & 22.8 & $\alpha 2.20 \mathrm{~m}$ & & 22.8 & $\alpha 2.19 \mathrm{~m}$ & & 18.9 & $\alpha 1.54 \mathrm{~m}$ & \\
\hline & & $\alpha 1.52$ ddd & $13.4,6.9,3.6$ & & $\beta 2.31 \mathrm{~m}$ & & & $\beta 2.27 \mathrm{~m}$ & & & $\beta 1.30 \mathrm{~m}$ & \\
\hline \multirow[t]{2}{*}{12} & 39.7 & $\beta 1.91 \mathrm{~d}$ & 11.5 & 33.1 & $\alpha 1.47 \mathrm{~m}$ & & 33 & $\alpha 1.43 \mathrm{~m}$ & & 35.4 & $\alpha 1.57 \mathrm{~m}$ & \\
\hline & & $\alpha 1.09 \mathrm{ddt}$ & $11.5,5,1.8$ & & $\beta 1.44 \mathrm{~m}$ & & & $\beta 1.46 \mathrm{~m}$ & & & $\beta 1.23 \mathrm{~m}$ & \\
\hline 13 & 44 & $2.64 \mathrm{t}$ & 5 & 34.3 & & & 34.2 & & & 38.8 & & \\
\hline \multirow[t]{2}{*}{14} & 33.2 & $\operatorname{pax} 1.47 \mathrm{~m}$ & & 33.6 & $\beta 1.99 \mathrm{dq}$ & $17,2.3$ & 33.6 & $\alpha 2.30 \mathrm{dt}$ & 17,2 & 133.9 & $5.47 \mathrm{t}$ & 1.7 \\
\hline & & peq $1.63 \mathrm{~m}$ & & & $\alpha 2.31 \mathrm{dq}$ & $17,2.3$ & & $\beta 1.99 \mathrm{dq}$ & $17,1.4$ & & & \\
\hline 15 & 49 & $2.05 \mathrm{t}$ & 2.5 & 147.4 & $5.75 \mathrm{dd}$ & $17.7,10.6$ & 147.2 & $5.74 \mathrm{dd}$ & $17.2,10.7$ & 146.5 & $5.68 \mathrm{dd}$ & $17.3,10.4$ \\
\hline \multirow[t]{2}{*}{16} & 155.7 & & & 110.8 & $4.89 \mathrm{dd}$ & $17.7,1$ & 110.9 & $4.88 \mathrm{dd}$ & $17.2,1.4$ & 113.5 & $4.82 \mathrm{dd}$ & $17.3,1.7$ \\
\hline & & & & & $4.91 \mathrm{dd}$ & $10.6,1$ & & 4.9 & $10.7,1.4$ & & $4.97 \mathrm{dd}$ & $10.4,1.7$ \\
\hline \multirow[t]{2}{*}{17} & 103.3 & $4.73 \mathrm{ddt}$ & $2.5,1.8,1.3$ & 24.8 & $0.95 \mathrm{~s}$ & & 24.8 & $0.94 \mathrm{~s}$ & & 29.2 & $1.02 \mathrm{~s}$ & \\
\hline & & $4.79 \mathrm{~m}$ & & & & & 119 & & & 119 & & \\
\hline \multirow[t]{2}{*}{18} & 22.8 & $1.22 \mathrm{~s}$ & & 70.9 & a $3.13 \mathrm{~d}$ & 10.9 & 27.5 & $1.0 \mathrm{~s}$ & & 22.4 & $1.27 \mathrm{~s}$ & \\
\hline & & & & & b $3.41 \mathrm{~d}$ & 10.9 & & & & & & \\
\hline \multirow[t]{2}{*}{19} & 64.5 & a $4.20 \mathrm{~d}$ & 11.2 & 17.5 & $0.87 \mathrm{~s}$ & & 15.3 & $0.89 \mathrm{~s}$ & & 64.4 & a $4.25 \mathrm{~d}$ & 11.1 \\
\hline & & b $3.31 \mathrm{dd}$ & $11.2,1.3$ & & & & & & & & b $3.34 \mathrm{dd}$ & $11.1,1.5$ \\
\hline 20 & 18.3 & & $0.98 \mathrm{~s}$ & 18.8 & $1.10 \mathrm{~s}$ & & 18.3 & $1.06 \mathrm{~s}$ & & 15.2 & $0.65 \mathrm{~s}$ & \\
\hline
\end{tabular}

${ }^{a}$ Assignments of the proton shifts were compared with those described by Lloyd et al. [29] and Dutra et al. [30]. 
Compound 2 was obtained as a colorless gum, $[\alpha]_{D}^{24}:+12.4\left(\mathrm{CHCl}_{3}\right), \mathrm{UV} \lambda_{\max }: 220$ and $254 \mathrm{~nm}$. The +ESI-MS spectrum returned a quasi-molecular ion at $m / z 303.2304[\mathrm{M}+\mathrm{H}]^{+}$, calculated for $\mathrm{C}_{20} \mathrm{H}_{31} \mathrm{O}_{2}: \mathrm{m} / z 303.2346$ (Figure S9, Supplementary Materials). The carbon resonance at $\delta 199.8$ (Table 2) indicated the presence of one ketone group. The deshielded carbon resonances of two quaternary $\mathrm{sp}^{2}$ carbons (C-8 at $\delta 129.1$ and C-9 at $\delta 165.8)$ indicated conjugation of a tetra-substituted $\mathrm{C}=\mathrm{C}$ double bond with the carbonyl group [31], whose position was confirmed at $\mathrm{C}-7$ by the ${ }^{1} \mathrm{H}-{ }^{13} \mathrm{C}$ long-range correlations between the protons $\mathrm{H}-14 \beta / \mathrm{H}-14 \alpha$ and the carbonyl carbon (Figure 2; Figure S13, Supplementary Materials). The presence of a hydroxyl group as already suggested by the mass spectrum showing a fragment at $m / z 285.2222\left[\mathrm{M}+\mathrm{H}-\mathrm{H}_{2} \mathrm{O}\right]^{+}$in the MS2 spectra, was confirmed by the NMR spectra, and the position was located at C-18 by comparison of the ${ }^{13} \mathrm{C}-\mathrm{NMR}$ shift value $(\delta 70.9)$ with literature data, which have shown that hydroxylation at $\mathrm{C}-18$ returns higher resonances $(\delta 71-75)$ than that at C-19 $(\delta 64-65)[30,31]$. Moreover, hydroxylation at the equatorial substituent C-18 causes a shielding effect at $C-5$, as becomes clear when 2 is compared with $\mathbf{1}$, where the hydroxylation is at C-19 (C-5: $\delta 43.2$ in Compound 2 as compared to $\delta 55.9$ in Compound 1, Table 2). The stereochemistry at the $\mathrm{C}$ ring was solved based on the correlations in a NOESY spectrum (Figure S15, Supplementary Materials), from which it became clear that the methyl group C-17 is in the $\beta$ and the vinyl group, hence in the $\alpha$-position at C-13 (Figure 2), so that the presence of an iso-pimarane was excluded and the compound unambiguously assigned the structure of a pimarane.

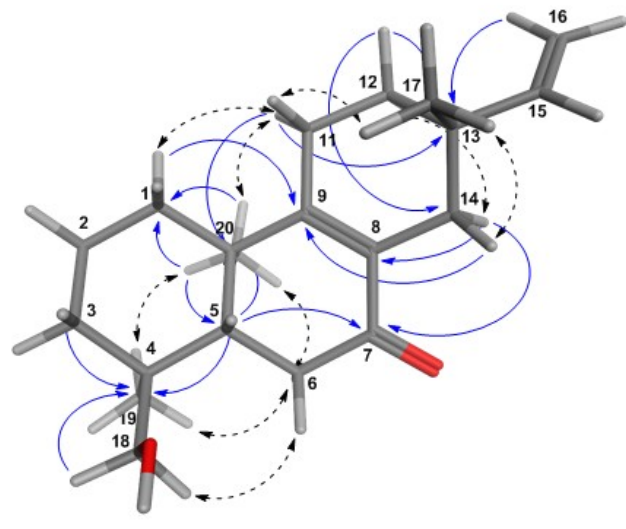

2

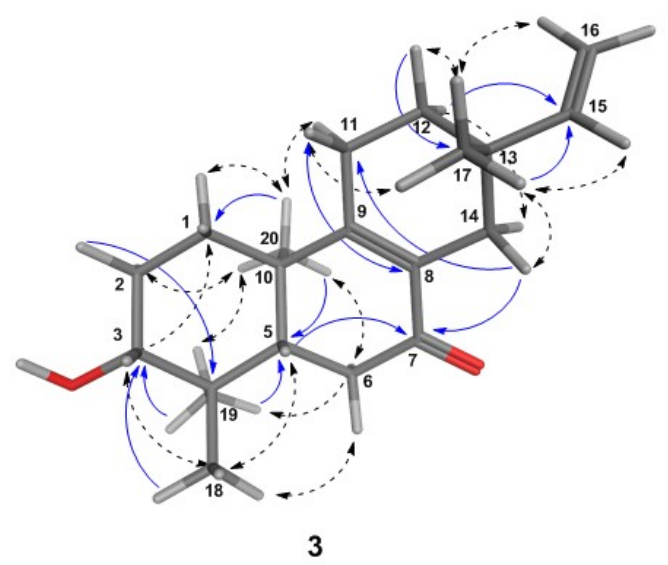

3

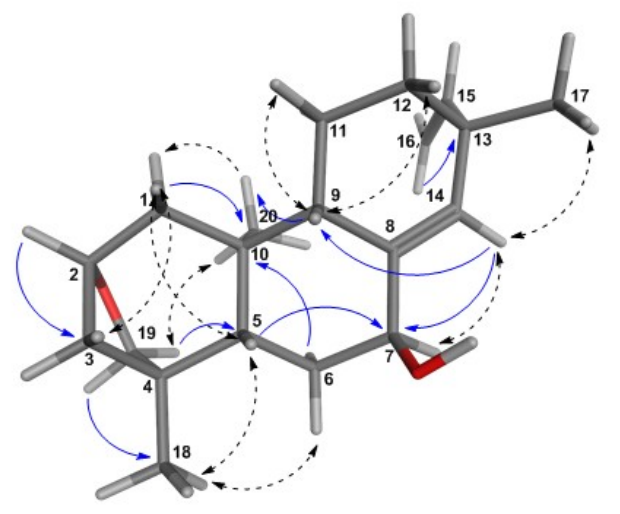

4

Figure 2. 3D-structures of the most energetically-favorable conformers for the ent-pimaranes 2-4 obtained after a low mode molecular dynamics (LMD) conformation search. Distances $(\leq 3.0 \AA)$ between the protons in the molecular model were in agreement with the experimental NOE effects, as shown by the NOESY correlations (dashed arrows). HMBC key correlations are also shown (blue arrows). 
Compound 3 was obtained as a white amorphous solid, $[\alpha]_{D}^{24}:-49.2, \mathrm{CHCl}_{3}, \mathrm{UV} \lambda_{\text {max }}: 220 \mathrm{~nm}$ and $250 \mathrm{~nm}$, and found to represent an isomer of Compound 2, as shown by its +ESI-QqTOF MS spectrum with a quasi-molecular ion at $m / z 303.2332[\mathrm{M}+\mathrm{H}]^{+}$, calculated for $\mathrm{C}_{20} \mathrm{H}_{31} \mathrm{O}_{2}: m / z 303.2346$ (Figure S16, Supplementary Materials). The NMR spectra were also very similar to those of $\mathbf{2}$, and the only major differences observed pointed towards a changed position of the $\mathrm{OH}$ group, which could be located at C-3, as indicated by the carbon resonance at $\delta 78.1$ and the methine proton signal at $\delta 3.29$ (Table 2; Figure S17, Supplementary Materials), which was correlated with $\mathrm{H}-2 \alpha$ at $\delta 1.69$ and $\mathrm{H}-2 \beta$ at $\delta 1.77$ in the COSY spectrum (Figure S21, Supplementary Materials). The relative $\alpha$-orientation of the $\mathrm{C}-3-\mathrm{OH}$ group follows from the coupling constants of $\mathrm{H}-3$, which appears as a dd with a large $(11.7 \mathrm{~Hz})$ and a smaller $(4.4 \mathrm{~Hz})$ coupling constant with the neighboring protons at $\mathrm{C}-2$, clearly showing that $\mathrm{H}-4$ is in the axial and the $\mathrm{OH}$ group, hence in the equatorial (in this case $\alpha$-). All observed NOEs (Figure 2) were in agreement with the 3D structure obtained by molecular modeling, confirming the relative configuration as depicted in Figure 1.

The absolute configuration of the closely-related isomers 2 and $\mathbf{3}$ was solved by comparison of their CD spectra with the theoretical spectrum simulated by a time-dependent density functional (TDDFT) calculation of Compound 3 and by comparison of the experimental CD spectra with literature data for structurally-related model compounds. Figure 3A shows a comparison of the experimental CD spectrum of 3 and the theoretical spectra simulated for the two enantiomers of this diterpene, i.e., as a normal and as an ent-pimarane. It becomes clear that the experimental curve with intense positive and negative Cotton effects (CEs) at 254 and $330 \mathrm{~nm}$ matches the simulated spectrum for the ent-pimarane quite well. Moreover, all three observed experimental CEs of both 2 and 3 (Figure 3B) are also in very good agreement with published data for a model compound containing the same chromophore in a very similar chiral environment corresponding to the ent-geometry [32] (Figure 3C), so that the assignment of the absolute configuration of both compounds to the ent-pimarane series is unambiguous. This is also in agreement with the literature on other diterpenes in Aldama species, where pimaranes or the normal series have not been found. Compound 2 hence represents ent-7-oxo-pimara-8,15-diene-18-ol, and Compound 3 is assigned the structure of ent-7-oxo-pimara-8,15-diene-3 $\beta$-ol. Both compounds have not been described as natural or synthetic products before, to the best of our knowledge.
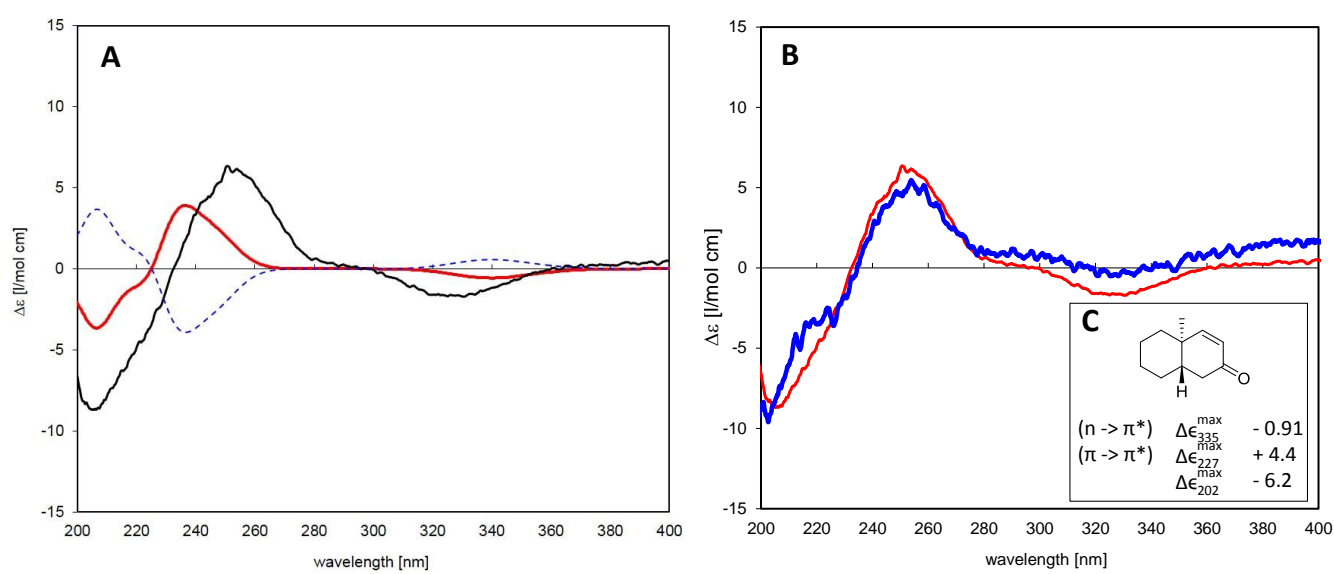

Figure 3. (A) Time-dependent density functional (TDDFT) calculated CD spectra for Compound 3 as a normal pimarane (blue, dashed) and ent-pimarane (red) in comparison with the experimental spectrum of the isolated compound (black); (B) comparison of CD spectra of Compounds $\mathbf{1}$ (blue) and 3 (red). Both compounds show essentially the same Cotton effects, so that they belong to the same series of diterpenes; (C) Correlation between the Cotton effect sign of a model enone in heptane that corresponds to the same absolute configuration as that observed in Compounds $\mathbf{1}$ and $\mathbf{3}$ (adapted from Lightner et al. [32]). 
Compound 4 was obtained as a white amorphous solid, $[\alpha]_{D}^{25}:-24.7\left(\mathrm{CHCl}_{3}\right), \mathrm{UV} \lambda_{\max }: 220 \mathrm{~nm}$ and revealed by its +ESI/QqTOF mass spectrum with a quasi-molecular ion at $m / z 303.2369[\mathrm{M}+\mathrm{H}]^{+}$, calculated for $\mathrm{C}_{20} \mathrm{H}_{31} \mathrm{O}_{2}: \mathrm{m} / z$ 303.2346 (Figure S24, Supplementary Materials) to be an isomer of 2 and 3. However, major differences in the NMR spectra showed the absence of the conjugated enone partial structure observed in $\mathbf{2}$ and 3 . Instead, the resonances of a trisubstituted double bond with resonances at $\delta 140.1$ (quaternary, C-8) and 133.9 (CH, C-14), whose position between C-8 and $\mathrm{C}-14$ was confirmed by the observed ${ }^{5} \mathrm{~J}$ long-range couplings of the corresponding methine proton (H-14) with the protons at the vinyl methylene group $\left(\mathrm{t},{ }^{5} J_{14,16 a}=1.7 \mathrm{~Hz},{ }^{5} J_{14,16 b}=1.7 \mathrm{~Hz}\right)$. The position of the hydroxyl group at C-7 was deduced from the couplings of $\mathrm{H}-7$ with the protons at C-6 (dd at $\delta 4.25$, with ${ }^{3} J_{7,6 a}=6.8 \mathrm{~Hz},{ }^{3} J_{7,6 b}=3.8 \mathrm{~Hz}$ ). Occurrence of two relatively small couplings of $\mathrm{H}-7$ can only be explained if it is in an equatorial (in this case $\alpha$-position), and the $\mathrm{OH}$ hence occupies the (axial) $\beta$-position at C-7. The fact that 4 is an isomer of $\mathbf{2}$ and $\mathbf{3}$, but lacks the carbonyl double bond or any other additional double bonds besides those at C- $8=\mathrm{C} 14$ and C-15=C-16 indicates that the compound must contain an additional ring. The resonances of oxygenated methine and methylene carbons at $\delta 81.0$ and $64.4 \mathrm{ppm}$ (C-2 and C-19, respectively) indicate that both carbons are bound to the remaining oxygen atom, which must hence form an ether bridge between these two carbons. The presence of a tetrahydrofuran ring involving C-2,3,4 and 19, as well as the oxygen atom was unambiguously confirmed by the ${ }^{1} \mathrm{H} /{ }^{13} \mathrm{C}$-correlations observed in the HMBC spectrum (Figure 2, Figure S28, Supplementary Materials). The stereochemistry in this part of the molecule, i.e., the relative orientation of C-3 and C-19 forming the cyclohexane and tetrahydrofuran rings, could be deduced from an NOE between the oxymethylene proton $\mathrm{H}-19 \mathrm{a}$ and the methyl group $\mathrm{CH}_{3}-20$ (Figure 2), which is only possible if they are both on the same side of the molecule. $\mathrm{CH}_{3}-20$ adopts an $\alpha$-orientation in ent-pimaranes, so that the same must hold true for the C-19-O-C-2 bridge. The relative configuration in a major part of the molecule could be determined from further NOESY correlations (Figure 2; Figure S30, Supplementary Materials). The relative configuration at C-13 (i.e., assignment of a pimarane or iso-pimarane) in the case of Compound 4 could not be solved on grounds of the NOESY spectrum. However, it has been reported that pimara-8(14),15-dienes and their ent-analogues show a deshielded resonance of $\mathrm{C}-17$ ( $\delta \mathrm{C}$ about $29 \mathrm{ppm})$ in comparison with the corresponding iso-pimarane and ent-isopimarane derivatives ( $\delta \mathrm{C}$ around $24 \mathrm{ppm}$ ) [31]. C-17 resonates at $29.2 \mathrm{ppm}$ in Compound 4 so that it can be assigned the relative configuration of a pimarane/ent-pimarane, i.e., the same as in Compounds 2 and 3. Due to the close structural similarity to the ent-pimaranes 2 and 3, the absolute stereochemistry should be that of an ent-pimarane, as well. Compound 4 thus represents ent-2S,4S-2,19-epoxy-pimara-8(14),15-diene-7 $\beta$-ol, a hitherto unknown natural product.

\subsection{In Vitro Antiprotozoal Activities}

The high activity of the crude extract against $T . b$. rhodesiense is easily explained by the presence of budlein A as a major constituent in the extract (see above and Figure S1, Supplementary Materials), which has previously been reported by our group to possess exceptionally strong activity against this pathogen in vitro [26]. However, in our ongoing investigations to predict the activity of compounds from Asteraceae, using chemometric methods ([27,28]; a full account of this study will be published separately), diterpenes, such as $\mathbf{1}$ and 2, were also suggested as active constituents of the dichloromethane extract of $A$. discolor. Therefore, the isolated diterpenes were tested against T. b. rhodesiense, T. cruzi, L. donovani and P. falciparum, as well as for cytotoxicity against mammalian cells (L6 cell line) using established protocols [33]. Moreover, pimarane and kaurane-type diterpenes have previously been reported to have some antiprotozoal activity $[17,34,35]$. The resulting $\mathrm{IC}_{50}$ values are reported in Table 3. The highest antiprotozoal activities were obtained for ent-pimaranes 1 against both $P$. falciparum and L. donovani and $\mathbf{2}$ against $P$. falciparum, against which they also showed significant selectivity (selectivity indices (SI) all $>10$ ). Their activity and selectivity against $T$. $b$. rhodesiense and T. cruzi were considerably lower. 
Table 3. $\mathrm{IC}_{50}$ (geometric mean of 2 experiments $\pm \mathrm{SE}$ ) of the isolated compounds $(\mu \mathrm{M})$ tested against T. b. rhodesiense, T. cruzi, L. donovani, P. falciparum and L6 cells. The selectivity index (SI) determined with L6 cells is also shown.

\begin{tabular}{cccccccccc}
\hline Comp. & T. $\boldsymbol{b}$. rhodesiense & SI & T. cruzi & SI & L. donovani & SI & P. falciparum & SI & L6 Cells \\
\hline $\mathbf{1}$ & $20.1 \pm 0.5$ & 2 & $55.6^{a}$ & 1 & $2.5 \pm 1.5$ & 16 & $3.5 \pm 0.2$ & 11 & $40.2 \pm 5.5$ \\
$\mathbf{2}$ & $24.3^{a}$ & 2 & $15.4^{a}$ & 3 & $18.2^{a}$ & 3 & $3.8^{a}$ & 13 & $48.3 \pm 5.9$ \\
$\mathbf{3}$ & $\mathrm{NA}$ & & $19.4^{a}$ & 4 & $13.8^{a}$ & 5 & $16.5 \pm 4.9$ & 4 & $69.3 \pm 10.9$ \\
$\mathbf{4}$ & $47.3 \pm 4.1$ & 2 & $58.9^{a}$ & 2 & $21.9^{a}$ & 5 & $16.1 \pm 6.1$ & 6 & $101.0 \pm 45.7$ \\
\hline Pos. controls & $0.025 \pm 0.0005$ & & $0.653 \pm 0.135$ & & $0.049 \pm 0.001$ & & $0.003 \pm 0.001$ & $0.008+0.001$ \\
\hline
\end{tabular}

T. b. rhodesiense (STIB 900 strain, trypomastigotes, pos.control: melarsoprol); T. cruzi (Tulahuen C4 strain, amastigotes, pos. control: benznidazole); L. donovani (MHOM-ET-67/L82 strain, amastigotes, pos. control: miltefosine); P. falciparum (NF54 strain, intra-erythrocytic stages, pos. control: chloroquine), cytotoxicity (L6-cell-line from rat-skeletal myoblasts, pos. control: podophyllotoxin); ${ }^{a}$ only one experiment was carried out to obtain the $\mathrm{IC}_{50}$; NA: not assayed due to the indication of a lack of activity in a prediction study (unpublished data).

\section{Discussion}

Compound 2 (ent-7-oxo-pimara-8,15-diene-18-ol) showed a relatively selective activity against P. falciparum and yielded the highest SI among the tested compounds $\left(\mathrm{IC}_{50}=3.85 \mu \mathrm{M} ; \mathrm{SI}=12.55\right.$; Table 3). There are only two reports on the antiprotozoal activity of isopimaranes, which also addressed the evaluation of the activity against P. falciparum [34,35]. In the work of Asili et al. [34], 8(9),15-isopimaradien-3 $\beta$-ol showed the most prominent in vitro antiplasmodial effect against P. falciparum strain 3D7 $\left(\mathrm{IC}_{50}=24.5 \mu \mathrm{M}\right)$. The study associated the antiplasmodial activity with a pronounced membrane-modifying effect on erythrocytes, e.g., to induce echinocytosis and cell lysis. The mentioned compound differed from the remaining compounds evaluated in the series in that it contained only a single oxygen at one end of the molecule, resulting in an amphiphilic character. In a similar manner, the congener 8(14),15-isopimaradien-3 $\beta, 19$-diol, in which the polar groups are located at one end of the molecule, induced echinocytosis at low concentrations and caused pronounced cell lysis, indicating, therefore, an indirect antiplasmodial effect [34]. This has also been highlighted in further studies with other NPs [36,37]. From this aspect, the ent-pimarane 2 with oxygen substituents at C-18 and C-7 is less likely to induce antiplasmodial effects in that manner in comparison with Compound 1, which presents such an amphiphilic character. However, the latter showed very similar activity with that of the former $\left(1, \mathrm{IC}_{50}=3.54 \mu \mathrm{M} ; 2, \mathrm{IC}_{50}=3.85 \mu \mathrm{M}\right)$, suggesting that the activity may not underlie such indirect effects on the erythrocyte host cell. Thus, to understand the mechanisms of action for the antiplasmodial and antileishmanial activities of these compounds, further investigations have to be carried out.

Within pimarane/isopimarane types, only 1,2,11-trihydroxypimara-8(14),15-diene and 1,11-dihydroxypimara-8(14),15-diene displayed relevant antiplasmodial activity with $\mathrm{IC}_{50}$ values of $27.4 \mu \mathrm{M} / \mathrm{mL}$ and $9.8 \mu \mathrm{M} / \mathrm{mL}$, respectively, against the P. falciparum $\mathrm{K}-1$ strain [35]. Thus, Compounds $\mathbf{1}$ and $\mathbf{2}$ are the most active diterpenes of these types against $P$. falciparum so far. Among kaurene and labdane-type diterpenes, stronger effects have been reported against T. $b$. rhodesiense $(0.76-1.49 \mu \mathrm{M})$ [38]. $11 \alpha$-Hydroxy-ent-16-kauren-15-one was notably active against T.b. brucei with an $\mathrm{IC}_{50}$ value of $0.761 \mu \mathrm{M}$ and a quite low SI (3.2), albeit the cytotoxicity was determined with a human embryonic cell line (MRC-5) [38].

Some ent-pimaranes from Aldama arenaria (Asteraceae) were previously reported to show in vitro activity against trypomastigote forms of $T$. cruzi (Y strain). The compounds with the highest effects were ent-15-pimarene-8 $\beta, 19$-diol and $3 \beta$-acetoxy-ent-8(14),15-pimaradiene, with $\mathrm{IC}_{50}$ of $116.5 \mu \mathrm{M}$ and $149.3 \mu \mathrm{M}$, respectively [17]. However, this level of activity, similar to that of the diterpenes 1 and 4 against T. cruzi, may be considered negligibly low. Although the $\mathrm{IC}_{50}$ of $\mathbf{2}$ and $\mathbf{3}$ were considerably lower, their activity is still much too low to consider them as useful hits against T. cruzi.

By now, there are not many reports on the antiprotozoal activity of pimarane/isopimarane and kaurane-type diterpenes [25]. In this study, not only the significant activity of ent-kaurane $\mathbf{1}$ against 
both P. falciparum and L. donovani and ent-pimarane 2 against P. falciparum was highlighted, but also their high SI ranging from 11-16. Therefore, these compounds can be considered as hits to be included in further steps of the investigation for their antiprotozoal activity, i.e., to test them against the parasites in in vivo models.

\section{Materials and Methods}

\section{General Procedures}

Analytical TLC was developed on silica gel plates $60 \mathrm{~F}_{254}$ (Merck Chemicals GmbH, Darmstadt, Germany) with EtOAc-hexane 2:1 (1.5\% acetic acid) as the mobile phase. TLC plates were observed under UV-light at wavelengths of $254 \mathrm{~nm}$ and $360 \mathrm{~nm}$, then sprayed with anisaldehyde-sulfuric acid reagent and heated on a hot plate [39]. Preparative HPLC separations were undertaken with a Jasco (Gross-Umstadt, Germany) prep.HPLC system (pump: PU-2087 plus; diode array detector MD 2018 plus; column thermostat CO 2060 plus; autosampler AS 2055 plus; LC Net II ADC Chromatography Data Solutions; sample injection loop: $2000 \mu \mathrm{L})$. Separations were performed using a preparative reverse phase column Reprosil 100 C-18 (5 $\mu \mathrm{m}, 250 \mathrm{~mm} \times 20 \mathrm{~mm}$, Macherey-Nagel, Düren, Germany) with binary gradients of the mobile phase. A flow rate of $12 \mathrm{~mL} / \mathrm{min}$ and a column-thermostat temperature of $40^{\circ} \mathrm{C}$ were used in all HPLC preparative separations. Chromatograms were recorded at 210-220, 254 and $280 \mathrm{~nm}$. Optical rotations were recorded in $\mathrm{CHCl}_{2}$ on a Jasco P-2000 polarimeter. UV spectra were extracted from the HPLC-UV-DAD chromatograms. CD spectra were recorded with a Jasco J-815 CD-spectropolarimeter in $\mathrm{MeOH}$.

\section{Plant Material}

Leaves of Aldama discolor (Baker) E.E.Schill. \& Panero (Syn. Viguiera discolor) were collected at Sacramento-MG, Brazil (GPS: 20 00'26.1" S and 047 $24^{\prime} 30.3^{\prime \prime} \mathrm{W}$ ) in November 2012. Plants were oven-dried at $40{ }^{\circ} \mathrm{C}$ for $48 \mathrm{~h}$. Voucher specimens were deposited under reference D.P.V.FALEIRO 01 at the Herbarium SPFR, University of São Paulo, Ribeirao Preto-SP, and at the Herbarium HUSC, University of Santos, Santos-SP, Brazil, and were identified by Dr. Mara Angelina Galvão Magenta.

Chromatographic Separation of the Dichloromethane Extract of Aldama discolor Leaves: Isolation of Compounds 1-4

Dried leaves of $A$. discolor (100 g) were powdered and extracted with $\mathrm{CH}_{2} \mathrm{Cl}_{2}(3 \times 1 \mathrm{~L}, 3 \times 24 \mathrm{~h})$ by maceration at room temperature to obtain the crude extract $(20 \mathrm{~g})$ after solvent evaporation. This was suspended in $\mathrm{MeOH}-\mathrm{H}_{2} \mathrm{O}(9: 1,300 \mathrm{~mL})$ and partitioned firstly with hexane $(3 \times 300 \mathrm{~mL})$. The $\mathrm{MeOH}-\mathrm{H}_{2} \mathrm{O}$ phase was evaporated until full removal of the methanol. The remaining solution was partitioned with $\mathrm{CH}_{2} \mathrm{Cl}_{2}(3 \times 250 \mathrm{~mL})$ after adding water to an equal volume. After evaporation of the solvents, the hexane-soluble fraction $(6.8 \mathrm{~g})$, the $\mathrm{H}_{2} \mathrm{O}$-soluble fraction $(3 \mathrm{~g})$ and the $\mathrm{CH}_{2} \mathrm{Cl}_{2}$-soluble fraction $(9.6 \mathrm{~g})$ were obtained. The $\mathrm{CH}_{2} \mathrm{Cl}_{2}$-soluble fraction $(9 \mathrm{~g})$ was separated on a silica gel column (800 g) packed with the initial mobile phase. The sample was eluted with a gradient of the mobile phase increasing the polarity of the mixture hexane-EtOAc $(7: 3, v / v)$, as follows: $2.5 \mathrm{~L}(7: 3), 2 \mathrm{~L}(1: 1)$, $2 \mathrm{~L}$ (7:3), followed by $1 \mathrm{~L}$ of EtOAc; flow: $0.8-1 \mathrm{~mL} / \mathrm{min}$. The first $1.5 \mathrm{~L}$ of eluent were collected as a single fraction, followed by 130 fractions of around $50 \mathrm{~mL}$. These were combined according to their TLC profiles. After the collection of these fractions, the column was further washed with EtOAc (2 L) and furnished a last fraction $(4.49 \mathrm{~g})$ containing budlein $\mathrm{A}(5)$ as a major constituent. Fractions $\mathrm{F}_{66-88}$ (130 mg) and $\mathrm{F}_{89-102}(204 \mathrm{mg}$ ) yielded Compounds 1 (3.6 mg), 2 (7.4 mg), 3 (2.4 mg), and 4 (12.4 mg) after purification by preparative HPLC. The mobile phase optimized for the HPLC prep. consisted of acidified water with $0.01 \%$ TFA (trifluoroacetic acid) (A) and $\mathrm{MeOH}(\mathrm{B})$ in gradient conditions: $60 \%-80 \%$ of B (15 min), $80 \%-90 \%$ of B (15-30 min), $90 \%-100 \%$ of B (30-37 min), 100\% of B (37-44 min) 
and two more minutes to return to the initial mobile phase. The retention times of Compounds 1-4 were $28.4 \mathrm{~min}, 36.6 \mathrm{~min}, 21.8 \mathrm{~min}$ and $23.2 \mathrm{~min}$, respectively.

\section{Chromatographic Analysis of the Plant Extract and Pure Compounds by UHPLC-MS}

The plant extract and its fractions were dissolved in $\mathrm{MeCN}$ at a defined concentration $(5 \mathrm{mg} / \mathrm{mL})$ and analyzed with UHPLC/ESI-QTOF MS/MS. Chromatographic separations were performed on a Dionex Ultimate 3000 RS Liquid Chromatography System with a Dionex Acclaim RSLC 120, C18 column $(2.1 \times 100 \mathrm{~mm}, 2.2 \mu \mathrm{m})$ using a binary gradient (A: water with $0.1 \%$ formic acid; $\mathrm{B}$ : acetonitrile with $0.1 \%$ formic acid) at $0.8 \mathrm{~mL} / \mathrm{min}$ : 0-9.5 min: linear from 5\% B-100\% B; 9.5-12.5 min: isocratic $100 \% \mathrm{~B} ; 12.5-12.6 \mathrm{~min}$ : linear from $100 \% \mathrm{~B}$ down to $5 \% \mathrm{~B} ; 12.6-15 \mathrm{~min}$ : isocratic $5 \%$ B. The injection volume was $5 \mu \mathrm{L}$. Eluted compounds were detected using a Dionex Ultimate DAD-3000 RS over a wavelength range of 200-400 nm and a Bruker Daltonics micrOTOF-QII quadrupole/time-of-flight mass spectrometer equipped with an Apollo electrospray ionization source in positive mode at $5 \mathrm{~Hz}$ over a mass range of $m / z$ 50-1000 using the following instrument settings: nebulizer gas nitrogen, 5 bar; dry gas nitrogen, $9 \mathrm{~L} / \mathrm{min}, 22{ }^{\circ} \mathrm{C}$; capillary voltage $4500 \mathrm{~V}$; end plate offset $-500 \mathrm{~V}$; transfer time $70 \mu \mathrm{s}$; collision gas nitrogen; collision energy and collision RF settings were combined for each single spectrum of 1000 summations as follows: 250 summations with $20 \%$ base collision energy, $130 \mathrm{Vpp}+250$ summations with $100 \%$ base collision energy, $500 \mathrm{Vpp}+250$ summations with $20 \%$ base collision energy and $130 \mathrm{Vpp}+250$ summations with $100 \%$ base collision energy and $500 \mathrm{Vpp}$. Base collision energy was $50 \mathrm{eV}$ for precursor ions with a $\mathrm{m} / z$ less than 500 and then linearly interpolated against $m / z$ up to a maximum of $70 \mathrm{eV}$ for precursor ions with a $m / z$ of up to 1000. Internal dataset calibration (HPCmode) was performed for each analysis using the mass spectrum of a $10 \mathrm{mM}$ solution of sodium formiate in $50 \%$ isopropanol that was infused during LC re-equilibration using a divert valve equipped with a $20-\mu \mathrm{L}$ sample loop.

\subsection{Structural Determination of the Isolated Compounds}

\subsubsection{General}

Structural elucidation was carried out using the mass spectrometry data of compounds and one-, as well as two-dimensional NMR techniques: ${ }^{1} \mathrm{H},{ }^{13} \mathrm{C}, \mathrm{HSQC}, \mathrm{HMBC}, \mathrm{COSY}$ and NOESY. The NMR spectra were recorded on an Agilent DD2 $600 \mathrm{MHz}$ spectrometer. All spectra were obtained in $\mathrm{CDCl}_{3}$ at room temperature. They were referenced to the solvent signals of $\mathrm{CDCl}_{3}\left({ }^{1} \mathrm{H} ; 7.260 \mathrm{ppm}\right)$ and $\mathrm{CDCl}_{3}\left({ }^{13} \mathrm{C} ; 77.000 \mathrm{ppm}\right)$. Spectra were processed and evaluated using MestReNOVA v. 10 (Mestrelab Research, Santiago de Compostela, Spain). Full structural elucidation of new structures, e.g., to clarify the relative configuration, was aided by molecular modeling using the Molecular Operations Environment (MOE, 2011.10). Structures were drawn in the different stereoisomeric forms, and each one was submitted to energy minimization using the MMFF94X force field and default parameters from the software. Following, the structures were subjected to a conformational search, using the low mode molecular dynamics (LMD) method, as implemented in MOE and the MMFF94Xforce field. For this, all items were set as default with an RMS gradient of $0.01 \mathrm{kcal} / \mathrm{mol}$ and an RMS distance of $0.1 \AA$. The obtained conformers were output into an MDBfile, and the distances between specific protons in the structure were measured whether either for the conformer with the lowest energy or for all conformers within an energy window of $4 \mathrm{kcal} / \mathrm{mol}$ above the most energetically-favorable geometry. Observed distances between the protons $(\leqslant 3 \AA)$ of the most energetically-favorable conformers in agreement with the presence of NOEs were compared with the experimental data from NOESY spectra for the determination of the final structure.

\subsubsection{Assignment of Absolute Configuration for ent-Pimaranes}

In order to decide unambiguously whether the isolated pimarane-type compounds belong to the normal or enantio (ent-)pimarane series, CD spectra of Compounds 2 and 3 were recorded and 
related to the theoretical spectrum of $3 /$ ent-3 calculated by time-dependent density functional theory (TDDFT) computations. To this end, a 3D molecular model of ent-4 was generated and geometry optimized as described previously. After energy minimization of six low energy conformers obtained in an LMD conformation search (MOE) with Gaussian W03 [40] using the B3LYP density functional and a $6-31 G(d, p)$ basis set, the populations of the six conformers were calculated using their energy differences and the Boltzmann equation. They were thus estimated to represent $25.4 \%, 24.8 \%, 21.1 \%$, $17.7 \%, 6.1 \%$ and $4.9 \%$ of the overall conformational equilibrium. TD-DFT calculations were performed for the first four conformers using the same density functional and basis set as above and considering the 30 lowest-energy electronic transitions for each conformer. The resulting rotatory strength vectors were converted into a simulated CD spectrum for each molecule species as described previously, e.g., in $[41,42]$. The individual spectra were averaged according to the equilibrium percentages mentioned above, which resulted in the simulated spectrum shown in Figure 3.

\subsection{Analytical Data for Compounds $\mathbf{1}-\mathbf{5}$}

ent-3- $\alpha$-hydroxy-kaur-16-en-18-ol (1): white amorphous solid; $[\alpha]_{D}^{24}$ : $-20.6\left(\mathrm{CDCl}_{3}\right)$; $\mathrm{UV}\left(\mathrm{H}_{2} \mathrm{O}-\mathrm{MeCN}\right) \lambda_{\max }$ : 225. +ESI MS (m/z): 229.1961, $269.2245\left[\mathrm{M}+\mathrm{H}-2\left(\mathrm{H}_{2} \mathrm{O}\right)\right]^{+}, 287.2402\left[\mathrm{M}+\mathrm{H}-\mathrm{H}_{2} \mathrm{O}\right]^{+} ; 305.2494$ $[\mathrm{M}+\mathrm{H}]^{+} ; 327.2322[\mathrm{M}+\mathrm{Na}]^{+} ;{ }^{1} \mathrm{H}$ and ${ }^{13} \mathrm{C}-\mathrm{NMR}\left(\mathrm{CDCl}_{3}\right)$, see Table 2.

ent-7-oxo-pimara-8,15-diene-18-ol (2): colorless gum, $[\alpha]_{D}^{24}:+12.4\left(\mathrm{CHCl}_{3}\right)$; $\mathrm{UV} \lambda_{\text {max }}: 220$ and $254 \mathrm{~nm}$. +ESI MS (m/z): 163.1145, 255.2149 [M + H - HCOH - $\left.\mathrm{H}_{2} \mathrm{O}\right]^{+}, 273.2222[\mathrm{M}+\mathrm{H}-\mathrm{HCOH}]^{+}, 285.2222$ $\left[\mathrm{M}+\mathrm{H}-\mathrm{H}_{2} \mathrm{O}\right]^{+}, 303.2304[\mathrm{M}+\mathrm{H}]^{+}, 325.2153[\mathrm{M}+\mathrm{Na}]^{+} ;{ }^{1} \mathrm{H}$ and ${ }^{13} \mathrm{C}-\mathrm{NMR}\left(\mathrm{CDCl}_{3}\right)$, see Table 2.

ent-7-oxo-pimara-8,15-diene-3 $\beta$-ol (3): white amorphous solid; $[\alpha]_{D}^{24}:-49.2\left(\mathrm{CDCl}_{3}\right)$; $\mathrm{UV}\left(\mathrm{H}_{2} \mathrm{O}-\mathrm{MeCN}\right)$ $\lambda_{\max }: 220$ and $250 \mathrm{~nm}$; + ESI MS $(\mathrm{m} / \mathrm{z}): 303.2369[\mathrm{M}+\mathrm{H}]^{+}, 325.2156[\mathrm{M}+\mathrm{Na}]^{+}, 605.4628[2 \mathrm{M}+\mathrm{Na}]^{+}$; ${ }^{1} \mathrm{H}$ and ${ }^{13} \mathrm{C}$-NMR $\left(\mathrm{CDCl}_{3}\right)$, see Table 2.

ent-2S,4S-2-19-epoxy-pimara-8(3),15-diene-7 $\beta$-ol (4): white amorphous solid; $[\alpha]_{D}^{25}$ : $-24.7\left(\mathrm{CHCl}_{3}\right)$; $\mathrm{UV}\left(\mathrm{H}_{2} \mathrm{O}-\mathrm{MeCN}\right) \lambda_{\max }: 220 \mathrm{~nm}$; +ESI MS $(\mathrm{m} / \mathrm{z}): 227.1842,267.2159\left[\mathrm{M}+\mathrm{H}-2\left(\mathrm{H}_{2} \mathrm{O}\right)\right]^{+}$, $285.2275\left[\mathrm{M}+\mathrm{H}-\mathrm{H}_{2} \mathrm{O}\right]^{+}, 303.2369[\mathrm{M}+\mathrm{H}]^{+}, 605.4666[2 \mathrm{M}+\mathrm{H}]^{+} ;{ }^{1} \mathrm{H}$ and ${ }^{13} \mathrm{C}-\mathrm{NMR}\left(\mathrm{CDCl}_{3}\right)$, see Table 2.

budlein A (5): white amorphous solid; $\mathrm{UV}\left(\mathrm{H}_{2} \mathrm{O}-\mathrm{MeCN}\right) \lambda_{\text {max }}$ : 220 and $275 \mathrm{~nm}$; +ESI MS (m/z): 275.0918 $[\mathrm{M}+\mathrm{H}$-acetate $)]^{+}, 375.1446[\mathrm{M}+\mathrm{H}]^{+}, 397.1253[\mathrm{M}+\mathrm{Na}]^{+}, 749.2790[2 \mathrm{M}+\mathrm{H}]^{+}, 771.2596[2 \mathrm{M}+\mathrm{Na}]^{+}$.

\subsection{In Vitro Assays for the Antiprotozoal Activity of the Crude Extract and Pure Compounds}

In vitro tests for the activity against Trypanosoma brucei rhodesiense (bloodstream trypomastigotes, STIB 900 strain), T. cruzi (amastigotes, Tulahuen C4 strain), Leishmania donovani (amastigotes, MHOM-ET-67/L82 strain), Plasmodium falciparum (intraerythrocytic forms, NF54 IEF strain), as well as for cytotoxicity against mammalian cells (L6-cell-line from rat-skeletal myoblasts) were performed according to established protocols as reported previously, e.g, in [33].

\section{Conclusions}

The investigation of the dichloromethane extract of $A$. discolor leaves led to the isolation of four structurally and biosynthetically related diterpenes, namely three new ent-pimar-15-ene derivatives $(2,3$ and 4$)$ as well as a known ent-kaurane (1). Furthermore, the known sesquiterpene lactone budlein A (5) was identified as a major compound. The strong growth inhibition of $A$. discolor extracts towards T. b. rhodesiense can be explained by the presence of budlein A as a major compound, since this STL reportedly possesses strong anti-T. $b$. rhodesiense activity [26]. Among the isolated diterpenes, ent-pimarane 2 showed considerable in vitro activity against $P$. falciparum, while ent-kaurane 1 presented the highest in vitro activity against both P. falciparum and L. donovani. Quite importantly, they returned significant $S I>10$, which makes them interesting candidates for in vivo tests. In order to better understand their mechanism of action, further studies will be necessary. 
Supplementary Materials: Supplementary materials can be accessed at: http://www.mdpi.com/1420-3049/ $21 / 9 / 1237 /$ s1.

Acknowledgments: M.N. acknowledges a four-year fellowship from the CAPES-DAAD cooperation (Deutscher Akademischer Austausch Dienst German Academic Exchange Service). The authors also thank Danniella P. Vasconcelos Faleiro for collecting the plant material and Mara Angelina Galvão Magenta for the identification of the species. This study is part of the collaboration works within the Research Network Natural Products against Neglected Diseases (ResNetNPND, http:/ / www.resnetnpnd.org/).

Author Contributions: M.S.N. performed the phytochemical investigation, isolation and characterization of the compounds, the data analysis and wrote the manuscript. F.B.D.C. conceded the plant material for the isolation step and revised the work. R.B and M.K. performed the biological activity tests. T.J.S. and F.B.D.C. conceived of and initiated the study. T.J.S. supervised the work at all stages, performed the theoretical calculations for the CD spectra and finalized the manuscript together with F.B.D.C.

Conflicts of Interest: The authors declare no conflict of interest.

\section{References}

1. Schilling, E.E.; Panero, J.L. A revised classificationcation of subtribe Helianthinae (Asteraceae: Heliantheae). I. Basal lineages. Bot. J. Linn. Soc. 2011, 140, 65-76.

2. Blake, S.F. A Revision of the Genus Viguiera; Contrib. Gray Herb. Harvard Univ.: Cambridge, MA, USA, 1918; Volume 54.

3. Meragelman, K.M.; Espinar, L.A.; Sosa, V.E.; Uriburu, M.L.; de la Fuente, J.R. Terpenoid constituents of Viguiera tucumanensis. Phytochemistry 1996, 41, 499-502.

4. Da Costa, F.B.; Schorr, K.; Arakawa, N.S.; Schilling, E.E.; Spring, O. Infraspecific variation in the chemistry of glandular trichomes of two Brazilian Viguiera species (Heliantheae; Asteraceae). J. Braz. Chem. Soc. 2001, 12, 403-407.

5. Delgado, G.; Vivar, A.R.D.E.; Herz, W.; Blake, V. Sesquiterpene lactones from Viguiera species. Phytochemistry 1982, 21, 1305-1308.

6. Delgado, G.; Cirdenas, H.; Pelez, G.; Vivar, A.R.D.; Pereda-Miranda, R. Terpenoids from Viguiera excelsa and Vigueira oaxacana. J. Nat. Prod. 1984, 4, 1042-1045.

7. Spring, O.; Zipper, R.; Klaiber, I.; Reeb, S.; Vogler, B. Sesquiterpene lactones in Viguiera eriophora and Viguiera puruana (Heliantheae; Asteraceae). Phytochemistry 2000, 55, 255-261.

8. Gao, F.; Miski, M.; Gage, D.A.; Norris, J.A.; Mabry, T.J. Terpenoids from Viguiera potosina. J. Nat. Prod. 1991, 30, 4172-4174.

9. Gao, F.; Miski, M.; Gage, D.A.; Mabry, T.J. Terpenoid constituents of Viguiera dentata. J. Nat. Prod. 1985, 48, 316-318.

10. Da Costa, F.B.; Albuquerque, S.; Vichnewski, W. Diterpenes and synthetic derivatives from Viguiera aspillioides with trypanomicidal activity. Planta Med. 1996, 62, 557-559.

11. Delgado, G.; Vivar, A.R.D.E.; Ortega, A.; Cardenas, J. Diterpenoids from Viguiera insignis. Phytochemistry 1983, 22, 1227-1230.

12. Delgado, G.; De Vivar, A.E.; Cardenas, J.; Pereda-Miranda, R.; Huerta, E. ent-Beyerene and ent-atisene diterpenes from Viguiera insignis. Phytochemistry 1984, 23, 2285-2288.

13. Zamilpa, A.; Tortoriello, J.; Navarro, V.; Delgado, G.; Alvarez, L. Antispasmodic and antimicrobial diterpenic acids from Viguiera hypargyrea roots. Planta Med. 2002, 68, 281-283.

14. Bohlmann, F.; Zdero, C.; Schmeda-Hirschmann, G.; Jakupovic, J.; Castro, V.; King, R.M.; Robinson, H. Heliangolide, trachyloban- und villanovan-derivate aus Viguiera arten. Liebigs Annal. Chem. 1984, 3, 495-502.

15. Guerrero, C.; Nava, A.L.; Quevedo, F.; Toscano, R.A.; Soriano-Garcia, M. Further constituents of Viguiera stenoloba and Viguiera pinnatilobata. Rev. Latinoam. Quim. 1986, 16, 126-128.

16. Ambrosio, S.R.; Schorr, K.; da Costa, F.B. Terpenoids of Viguiera arenaria (Asteraceae). Biochem. Syst. Ecol. 2004, 32, 221-224.

17. Ambrosio, S.R.; Arakawa, N.S.; Esperandim, V.R.; de Albuquerque, S.; da Costa, F.B. Trypanocidal activity of pimarane diterpenes from Viguiera arenaria (Asteraceae). Phytother. Res. 2008, 22, 1413-1415.

18. Villarreal, M.L.; Alvarezb, L.; Alonsoa, D.; Navarroa, V.; Garciab, P.; Delgadoc, G. Cytotoxic and antimicrobial screening of selected terpenoids from Asteraceae species. J. Ethnopharmacol. 1994, 42, 25-29. 
19. Carvalho, T.C.; Furtado, N.A.J.C.; Veneziani, R.C.S.; Heleno, V.C.G.; Souza, M.G.M.; Martins, C.H.G.; Franca, U.D.; Campinas, D. Antimicrobial activity of diterpenes from Viguiera arenaria against Endodontic Bacteria. Molecules 2011, 8, 543-551.

20. Souza, T.; Furtado, N.A.J.C.; Heleno, V.C.G.; Martins, C.H.G.; Da, F.B.; Severiano, M.E.; Silva, A.N.; Veneziani, R.C.S.; Ambrósio, S.R. Antimicrobial ent-pimarane diterpenes from Viguiera arenaria against gram-positive bacteria. Fitoterapia 2009, 80, 432-436.

21. Chagas-Paula, D.A.; Oliveira, T.B.; Faleiro, D.P.V.; Oliveira, R.B.; Costa, F.B.D. Outstanding anti-inflammatory potential of selected Asteraceae species through the potent dual inhibition of Cyclooxygenase-1 and 5-Lipoxygenase. Planta Med. 2015, 81, 1296-1307.

22. Marquina, S.; Maldonado, N.; Gardun, M.L.; Aranda, E.; Villarreal, M.L.; Navarro, V.; Bye, R.; Delgado, G.; Alvarez, L. Bioactive oleanolic acid saponins and other constituents from the roots of Viguiera decurrens. Phytochemistry 2001, 56, 93-97.

23. Guillet, G.; Chauret, D.; Arnason, J.T. Phototoxic polyacetylenes from Viguiera annua and adaptations of a Chrysomelide Beetle, Zygogramma continua, feeding on this plant. Phytochemistry 1997, 45, 695-699.

24. Ambrosio, S.R.; Tirapelli, C.R.; Fernando, B.; Oliveira, A.M.D. Kaurane and pimarane-type diterpenes from the Viguiera species inhibit vascular smooth muscle contractility. Life Sci. 2006, 79, 925-933.

25. Schmidt, T.J.; Khalid, S.A.; Romanha, A.J.; Alves, T.M.; Biavatti, M.W.; Brun, R.; da Costa, F.B.; de Castro, S.L.; Ferreira, V.F.; de Lacerda, M.V. The potential of secondary metabolites from plants as drugs or leads against protozoan neglected diseases-Part I. Curr. Med. Chem. 2012, 19, 2128-2175.

26. Schmidt, T.J.; da Costa, F.B.; Lopes, N.P.; Kaiser, M.; Brun, R. Silico prediction and experimental evaluation of furanoheliangolide sesquiterpene lactones as potent agents against Trypanosoma brucei rhodesiense. Antimicrob. Agents Chemother. 2014, 58, 325-332.

27. Nogueira, M.S. The Use of Chemometric and Chemoinformatic Tools for Identification and Targeted Isolation of Compounds from Asteraceae with Antiprotozoal Activity. Ph.D. Thesis, IPBP, University of Münster, Münster, Germany, 2016; p. 253.

28. Nogueira, M.S.; da Costa, F.B.; Magenta, M.A.; Kaiser, M.; Brun, R.; Schmidt, T.J. Screening of some Asteraceae to discover new active compounds against Trypanosoma brucei by metabolite profiling and PLS analysis. Planta Med. 2013, 79, SL4.

29. Lloyd, H.A.; Fallis, A. Terpene alcohols of Helichrysum dendroideum. Tetr. Lett. 1967, 48, 4891-4895.

30. Dutra, L.M.; Bomfim, L.M.; Rocha, S.L.A.; Nepel, A.; Soares, M.B.P.; Barison, A.; Costa, E.V.; Bezerra, D.P. ent-Kaurane diterpenes from the stem bark of Annona vepretorum (Annonaceae) and cytotoxic evaluation. Bioorgan. Med. Chem. Lett. 2014, 24, 3315-3320.

31. Seca, A.M.L.; Pinto, D.C.G.A.; Silva, A.M.S. Structural elucidation of pimarane and isopimarane diterpenoids: The ${ }^{13}$ C-NMR contribution. Nat. Prod. Commun. 2008, 3, 399-412.

32. Lightner, D.A.; Gurst, E.J. Organic Analysis and Stereochemistry from Circular Dichroism Spectroscopy; Wiley-VCH: New York, NY, USA, 2000; p. 487.

33. Schmidt, T.J.; Nour, A.M.M.; Khalid, S.A.; Kaiser, M.; Brun, R. Quantitative structure-Antiprotozoal activity relationships of sesquiterpene lactones. Molecules 2009, 14, 2062-2076.

34. Asili, J.; Lambert, M.; Ziegler, H.L.; Stærk, D.; Sairafianpour, M.; Witt, M.; Asghari, G.; Ibrahimi, I.S.; Jaroszewski, J.W. Erythrocyte membrane and on Plasmodium falciparum growth in the erythrocyte host cells. J. Nat. Prod. 2004, 67, 631-637.

35. Thongnest, S.; Mahidol, C.; Sutthivaiyakit, S.; Ruchirawat, S. Oxygenated pimarane diterpenes from Kaempferia marginata. J. Nat. Prod. 2005, 68, 1632-1636.

36. Ziegler, H.L.; Franzyk, H.; Sairafianpour, M.; Tabatabai, M.; Tehrani, M.D.; Bagherzadeh, K.; Hägerstrand, H.; Stærk, D.; Jaroszewski, J.W. Erythrocyte membrane modifying agents and the inhibition of Plasmodium falciparum growth: Structure-activity relationships for betulinic acid analogues. Bioorgan. Med. Chem. 2004, 12, 119-127.

37. Ziegler, H.L.; Hansen, H.S.; Staerk, D.; Christensen, S.B.; Hägerstrand, H.; Jaroszewski, J.W. The antiparasitic compound licochalcone $\mathrm{A}$ is a potent echinocytogenic agent that modifies the erythrocyte membrane in the concentration range where antiplasmodial activity is observed. Antimicrob. Agents Chemother. 2004, $48,4067-4071$. 
38. Otoguro, K.; Iwatsuki, M.; Ishiyama, A.; Namatame, M.; Nishihara-Tukashima, A.; Kiyohara, H.; Hashimoto, T.; Asakawa, Y.; Mura, S.; Yamada, H. In vitro antitrypanosomal activity of plant terpenes against Trypanosoma brucei. Phytochemistry 2011, 72, 2024-2030.

39. Wagner, H.; Bladt, S. Plant Drug Analysis: A Thin Layer Chromatography Atlas, 2nd ed.; Springer: Berlin, Germany, 2001; p. 383.

40. Frisch, M.J.; Trucks, G.W.; Schlegel, H.B.; Scuseria, G.E.; Robb, M.A.; Cheeseman, J.R.; Montgomery, J.A., Jr.; Vreven, T.; Kudin, K.N.; Burant, J.C.; et al. Gaussian 03, Revision C.02, 2004; Gaussian, Inc.: Wallingford, CT, USA, 2004.

41. Schmidt, T.; Vößing, S.; Klaes, M.; Grimme, S. An aryldihydronaphthalene lignan with a novel type of ring system and further new lignans from Linum perenne L. Planta Med. 2007, 73, 1574-1580.

42. Barbic, M.; Schmidt, T.J.; Jügenliemk, G. Novel phenyl-1-benzoxepinols from butcher's broom (Rusci rhizoma). Chem. Biodivers. 2012, 9, 1077-1083.

Sample Availability: Samples of compounds 1-4 are available from the corresponding author on request.

(C) 2016 by the authors; licensee MDPI, Basel, Switzerland. This article is an open access article distributed under the terms and conditions of the Creative Commons Attribution (CC-BY) license (http://creativecommons.org/licenses/by/4.0/). 